\title{
Anomalous Property of Liquid Pb-Bi Alloys Determined by EMF and Density Measurements*
}

\author{
By Kazuhisa Okajima** and Hiroshi Sakao**
}

\begin{abstract}
The present study was performed in an attempt to confirm the existence of $\mathrm{E} E$ zones in liquid $\mathrm{Pb}-\mathrm{Bi}$ alloys by employing emf and density measurements.

It was made clear by density measurements that the $\mathrm{E} E$ zones in the liquid alloys were related to the pre-freezing anomaly of pure lead and that the temperature widths of the zones were 20 to $30 \mathrm{~K}$.

The compositional dependence of the $\mathrm{E} E$ zone was found to correlate well with that of excess stability.
\end{abstract}

(Received November 25, 1987)

Keywords: anomalous property, liquid lead-bismuth alloy, electromotive force method, method of density measurements, pre-freezing anomaly, E E zone, excess stability

\section{Introduction}

A previous paper ${ }^{(1)}$ has reported the anomaly in liquid alloys that "E E zones" exist at temperatures close to the freezing point of component metal. This alloy anomaly originates from a pre-freezing anomaly of the component metal. Therefore, the present study was initially performed in order to confirm the existence of $\mathrm{E} \mathrm{E}$ zones in liquid $\mathrm{Pb}-\mathrm{Bi}$ alloys by employing the emf technique. Subsequently, in order to determine whether the $\mathrm{E} \mathrm{E}$ zone can exist in liquid alloys and is related to the prefreezing anomaly of the pure component metal, density measurements were performed.

\section{Experimental Procedure}

Metals of 99.9 to 99.9999 percent purites and chlorides of high-purity commercial grade were used.

The following concentration cell was constructed by employing an $\mathrm{H}$-shaped container made of a hard glass:

$$
\begin{aligned}
& \mathrm{Pb}-\mathrm{Sb}\left(1, N_{\mathrm{Pb}}=0.825\right) \mid \mathrm{KCl}-\mathrm{ZnCl}_{2} \\
& \quad-\mathrm{PbCl}_{2}(1) \mid \mathrm{Pb}-\mathrm{Bi}(1) .
\end{aligned}
$$

* This paper was presented at the 1978 and 1987 Autumn Meetings of the Japan Institute of Metals.

** Department of Metallurgy, Faculty of Engineering, Nagoya University, Nagoya 464, Japan.
The experimental apparatus and procedure were essentially the same as those described in the previous papers ${ }^{(1)(2)}$.

After the cell was constructed, an inert gas atmosphere of argon was established by evacuating and gas flushing. Then, the furnace temperature was raised to $690 \mathrm{~K}$, emf measurements were performed with decreasing temperature and the emf-temperature relationship was obtained. The first cooling run was performed from 690 to $550 \mathrm{~K}$ and lasted about 7 ks. After reheating to $690 \mathrm{~K}$, the second cooling run was performed until $525 \mathrm{~K}$. All measurements were performed for a period of about $20 \mathrm{ks}$ after the cell construction. If a standard electrode of pure lead is employed, direct measurements relative to liquid lead are impossible under $600 \mathrm{~K}$. Therefore, to make such measurements possible until $525 \mathrm{~K}$, liquid $\mathrm{Pb}-\mathrm{Sb}$ alloy of eutectic composition was used as the standard electrode.

The apparatus employed for determining the density of the liquid alloys is illustrated in Fig. 1. Essentially the same apparatus made of a hard glass as described previously ${ }^{(3)(4)}$ was employed with the modification that the lower part of the melting tube (I. D. $20 \mathrm{~mm}$ ) was blown up to I. D. $35 \mathrm{~mm}$ so that sampling was possible eight or nine times.

The experimental procedure was also nearly the same as described previously. About $10 \mathrm{~g}$ of $\mathrm{KCl}-\mathrm{ZnCl}_{2}$ salt $\left(N_{\mathrm{KCl}}=0.458\right.$, melting tem- 


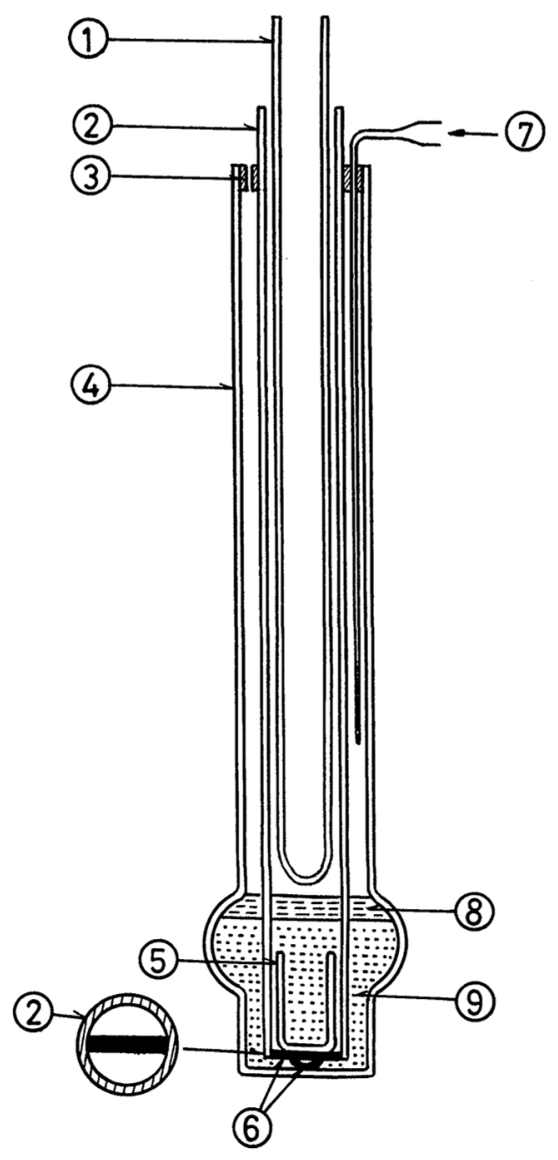

Fig. 1 Apparatus for determining density of the liquid $\mathrm{Pb}-\mathrm{Bi}$ alloys.

(1) Glass stick for pressing on

(2) Glass tube

(3) Silicon-rubber plug

(4) Melting tube

(5) Picnometer vessel

(6) Glass plank and fastener

(7) Argon gas

(8) Molten $\mathrm{KCl}-\mathrm{ZnCl}_{2}$ salts

(9) Liquid alloy

perature $503 \mathrm{~K}$ ) was put into a melting tube and melted by raising the temperature. Then, the chlorides were dehydrated by adding a small amount of $\mathrm{NH}_{4} \mathrm{Cl} .170$ to $200 \mathrm{~g}$ of lead and bismuth accurately weighed out to correspond to the required alloy composition was put into the tube and agitated sufficiently with a glass rod. At the starting temperature of about $690 \mathrm{~K}$, a glass tube containing both the picnometer vessel and the glass rod was lowered into the melting tube to a position about $1 \mathrm{~cm}$ above the molten salt to preheat it. The temperature distribution was $\pm 1 \mathrm{~K}$ in the range of $8 \mathrm{~cm}$ around the center of the furnace. Argon atmosphere was established by purified argon gas flow. After preheating for $1.2 \mathrm{ks}$, the glass tube was immersed into the liquid alloy and held for about $0.3 \mathrm{ks}$. The picnometer vessel was closed by pressing the glass rod against it and then the glass tube was drawn out together with the picnometer. A short while after cooling, the picnometer vessel was broken down, the alloy sample was taken out, washed with alcohol and weighed accurately. The density measurements were carried out during cooling runs from about $690 \mathrm{~K}$ and one cooling run lasted about $22 \mathrm{ks}$. The picnometric volume was calibrated in advance with mercury of known density.

\section{Experimental Results}

\section{Experimental results obtained by the emf method}

Figure 2 shows the result of the experiment performed in order to confirm whether the anomaly exists in the liquid $\mathrm{Pb}-\mathrm{Sb}$ alloy employed as the standard electrode. The experimental procedure was the same as described previously ${ }^{(1)}$, that is, the cell: $\mathrm{Pb}(\mathrm{l})$ $\left|\mathrm{KCl}-\mathrm{LiCl}-\mathrm{PbCl}_{2}(\mathrm{l})\right| \mathrm{Pb}-\mathrm{Sb}\left(1, N_{\mathrm{Pb}}=0.825\right)$ was employed. It is evident that the extent of the anomaly is very small due to the characteristic of the eutectic composition and therefore would have only a minor effect on the accuracy of determining the $\mathrm{E} E$ zone of the liquid alloys. The alloy characteristic of the eutectic

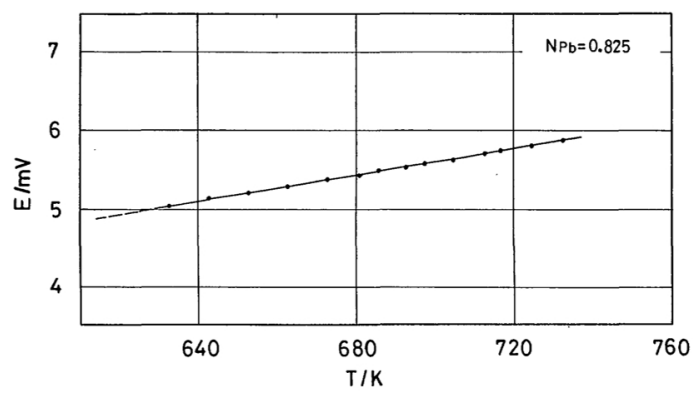

Fig. 2 Relationship between emf and temperature in the liquid $\mathrm{Pb}-\mathrm{Sb}$ alloy of the eutectic composition. 


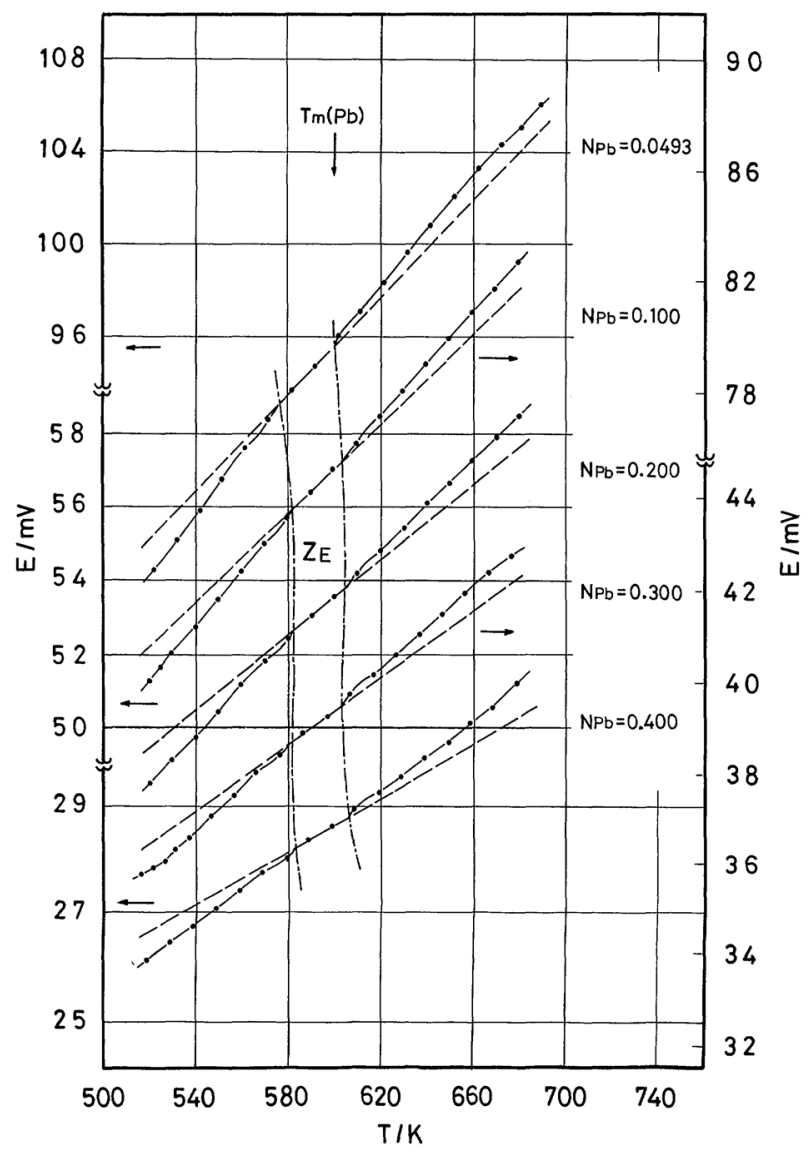

Fig. 3 Relationship between emf and temperature in the composition range $N_{\mathrm{Pb}}=0.0493-0.400$.

$T_{\mathrm{m}}(\mathrm{Pb})$ : Melting point of lead, $\mathrm{Z}_{\mathrm{E}}$ : E E zone in the emf measurements.

composition has been described previously ${ }^{(1)}$.

Two cooling half-cycles showed consistent results at $N_{\mathrm{Pb}}=0.0493$ to 0.700 . On the other hand, some disagreements were seen between the first and the second runs for the compositions above $N_{\mathrm{Pb}}=0.720$ somewhat similar to that reported in the previous paper ${ }^{(2)}$. Data of the second cooling runs will be employed here, though it has already been made clear that there are no significant differences in the break temperatures in repeated cooling half-cycles ${ }^{(2)}$. Thus, the time-dependence of the $\mathrm{E} \mathrm{E}$ zone anomaly in density measurements will not be considered as being significant.

Figures 3 to 5 show the E E zones determined from the emf data of the second cooling runs. The broken lines were drawn empirically for the sake of clarifying the anomalies. The extent of the breaks at $N_{\mathrm{Pb}}=0.049$ to 0.5 is smaller compared with that of the other composition range, but this is probably due to a simpler liquid structural characteristic.

The activities of lead are calculated from the emf values corrected by employing the extrapolated value in Fig. 2 and compared with the values reported in the literature ${ }^{(5)(6)}$ in Fig. 6 , indicating that there is satisfactory agreement.

\section{Experimental results of density measure- ments}

Of special importance in density measurements is whether confirmation can be obtained of the existence of a zone corresponding 


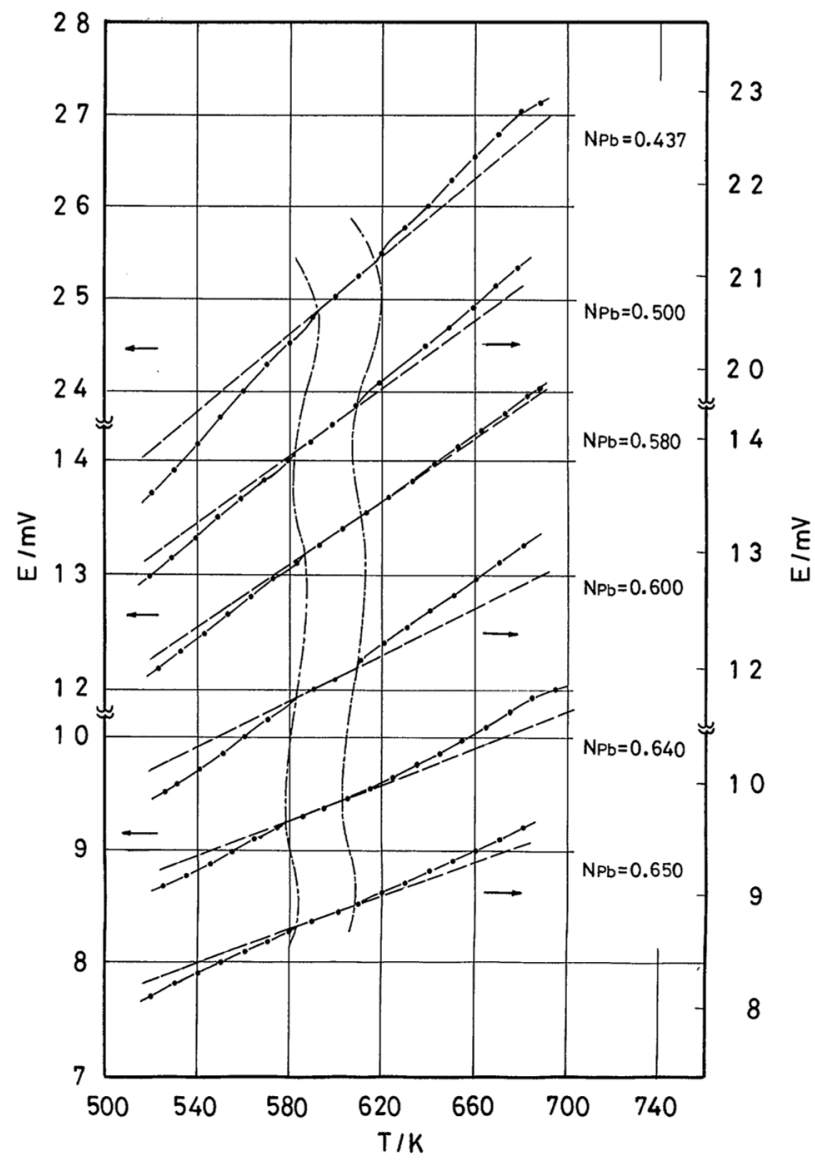

Fig. 4 Relationship between emf and temperature in the composition range $N_{\mathrm{Pb}}=0.437-0.650$.

to the $\mathrm{E} \mathrm{E}$ zone in pure liquid metals. Figure 7 shows the temperature variations of the density of pure lead and bismuth. A significant feature of the density curves for these pure metals is the fact that the temperaturedependence of the density becomes linear around a $20 \mathrm{~K}$ interval close to the freezing temperature while it was wavy at higher temperatures. This narrow temperature range between $\mathrm{A}$ and $\mathrm{B}$, seems very important and seems to reflect the formation of the $\mathrm{E} \mathrm{E}$ zone of the liquid alloys.

Figure 8 shows the measured density of the liquid alloys, in which flat portions of the density-temperature relationships corresponding to the $\mathrm{E} \mathrm{E}$ zone are observed distinctly at almost all compositions except at $N_{\mathrm{Pb}}=0.800$. The behavior of the emf as well as the density at $N_{\mathrm{Pb}}=0.800$, i.e. deviations of both data from the broken lines, had consistent trends in that they differed especially from those of the other compositions. A similar situation ${ }^{(2)(7)}$ has frequently been noted as the anomalous behavior of the emf at $N_{\mathrm{i}}=0.8$ and 0.9 .

These density data are further proof in a support of the anomaly of the $\mathrm{E} E$ zone existing in liquid alloys.

\section{Discussion}

In the present study, the $\mathrm{E} \mathrm{E}$ zone of the bismuth component was not considered because of the restricted temperature range of measurements.

Figures 9 and 10 show comparisons between the measured values of the densities and 


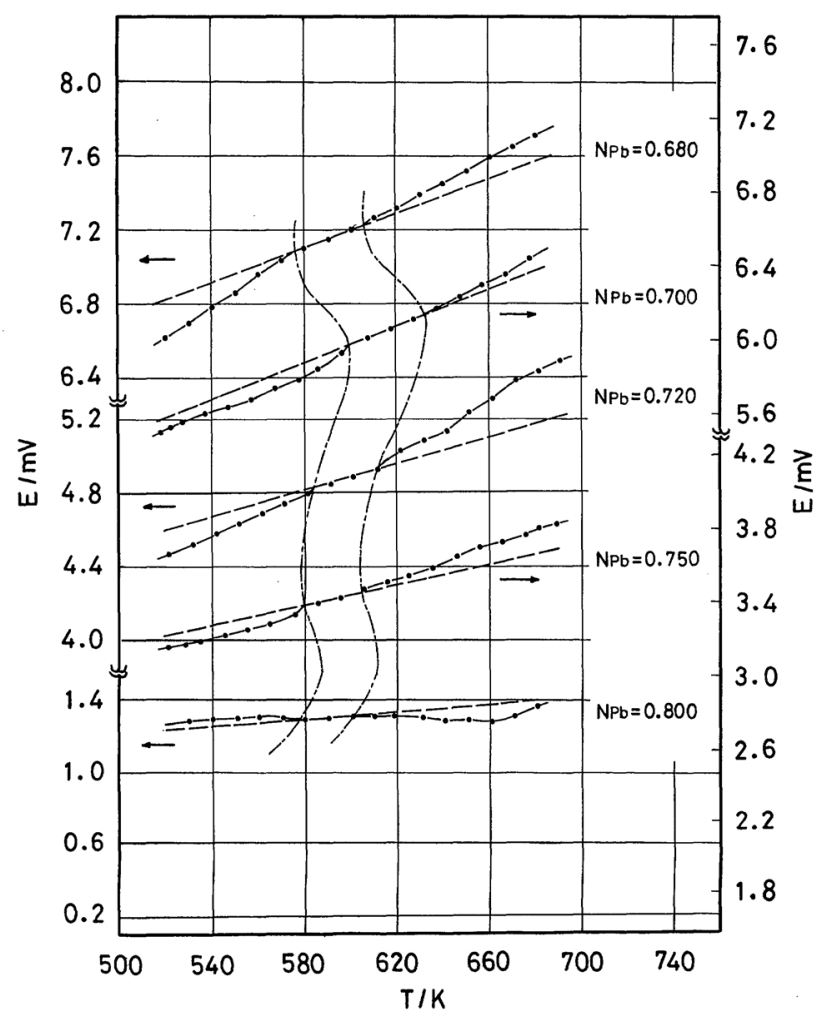

Fig. 5 Relationship between emf and temperature in the composition range $N_{\mathrm{Pb}}=0.680-0.800$.

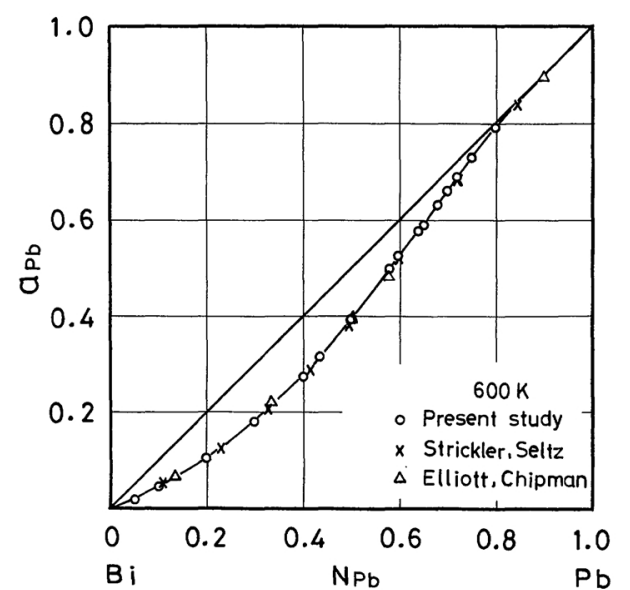

Fig. 6 Activities of component lead in liquid $\mathrm{Pb}-\mathrm{Bi}$ alloys.
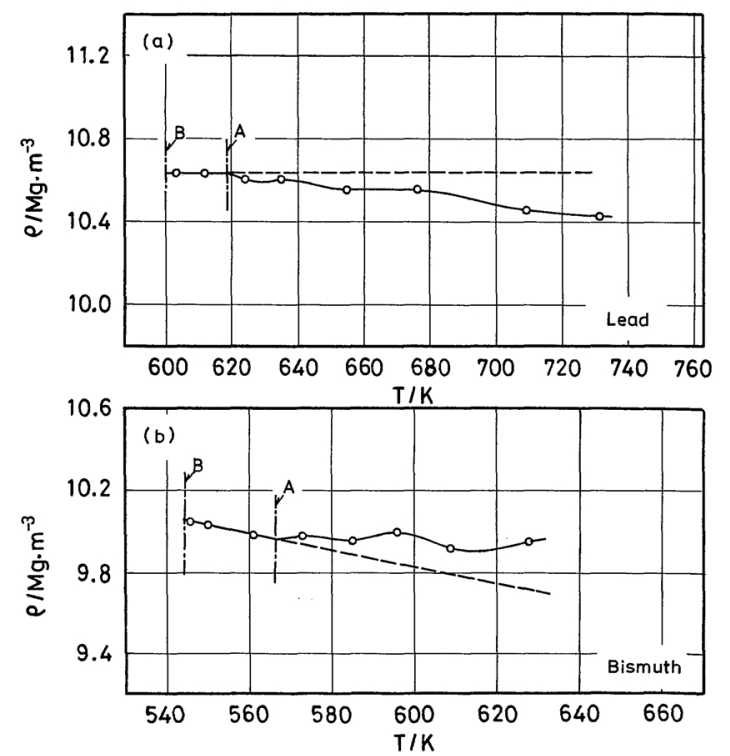

Fig. 7 Relationship between density and temperature of pure liquid lead and bismuth. 


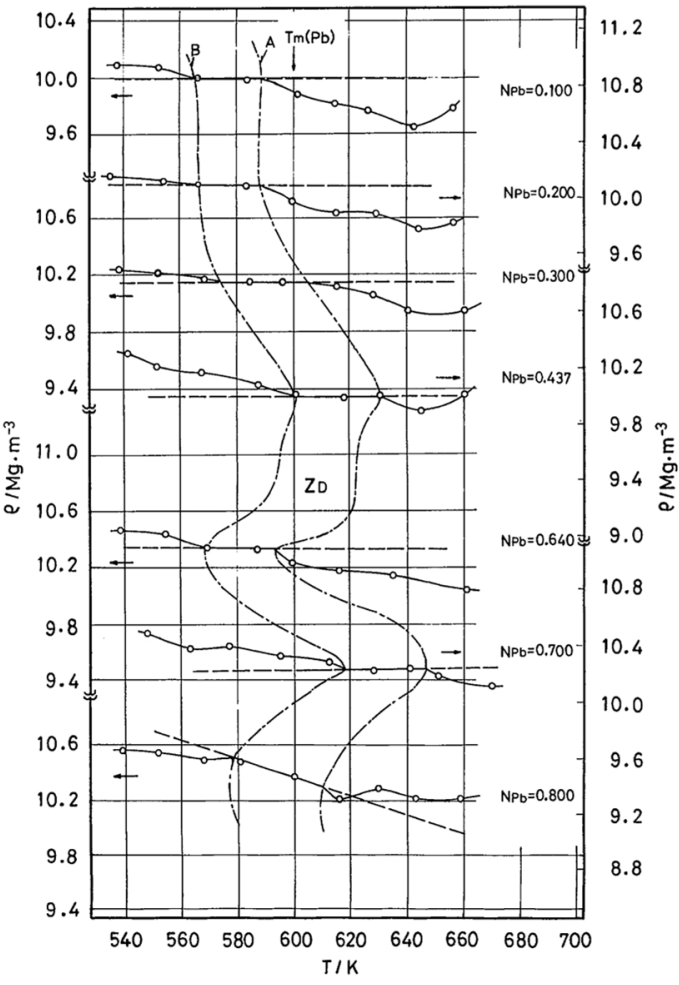

Fig. 8 Relationship between density and temperature of liquid $\mathrm{Pb}-\mathrm{Bi}$ alloys. $\mathrm{Z}_{\mathrm{D}}$ : $\mathrm{E} \mathrm{E}$ zone in the density measurements.

published values $^{(3)(4)(8)-(13)}$ for pure liquid lead and bismuth, indicating good agreement.

Figure 11 shows the present values of the density at $623 \mathrm{~K}$ for the liquid $\mathrm{Pb}-\mathrm{Bi}$ alloys compared with published values ${ }^{(14)}$, in which the density curve behaves anomalously in a manner similar to that described previously ${ }^{(15)}$.

Pre-melting and after-melting (i.e. pre-freezing) anomalies in pure metals have been reported previously ${ }^{(16)-(18)}$. A pre-freezing anomaly of about $30 \mathrm{~K}$ width has been reported by density measurements ${ }^{(19)}$. The present study shows a similar anomaly of about $20 \mathrm{~K}$ width for pure metals. The reason for the existence of the $\mathrm{E} \mathrm{E}$ zone in liquid alloys could be attributed to the pre-freezing anomaly of the pure component metal.

Figure 12 shows a comparison between two $E$ zones, $Z_{E}$ and $Z_{D}$, obtained in both the emf and density measurements. Agreements at $N_{\mathrm{Pb}}=0.2$ etc. are somewhat poor, but the temperature differences between the two zones are small and generally under $20 \mathrm{~K}$. Also, Fig. 12 indicates that there is good correspondence between the compositional dependence of the $\mathrm{E}$ $E$ zone and that of excess stability calculated from the activity values $a_{\mathrm{Pb}}$ at $600 \mathrm{~K}$. A similar situation has already been found in the previous paper ${ }^{(1)}$.

The emf measurements give an information of surface phases of the liquid alloys as known from the fact that this method is based on the electrochemical reaction between the interfaces of pure liquid metal-electrolyte and liquid alloy-electrolyte. On the other hand, the density is a bulk property to a great extent rather than a surface one. It has already been

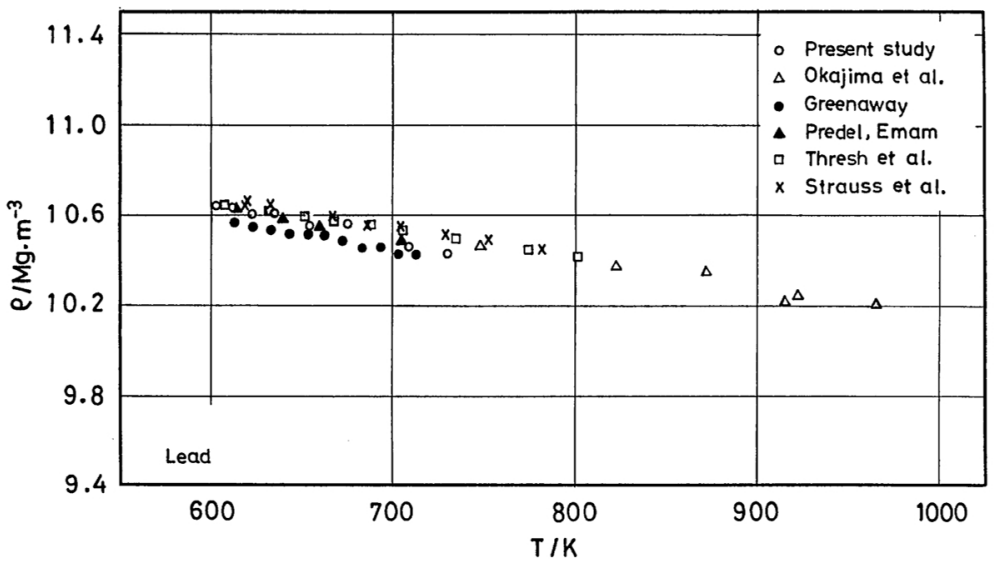

Fig. 9 Comparison of published values with values obtained by the present study on the density of the pure liquid lead. 


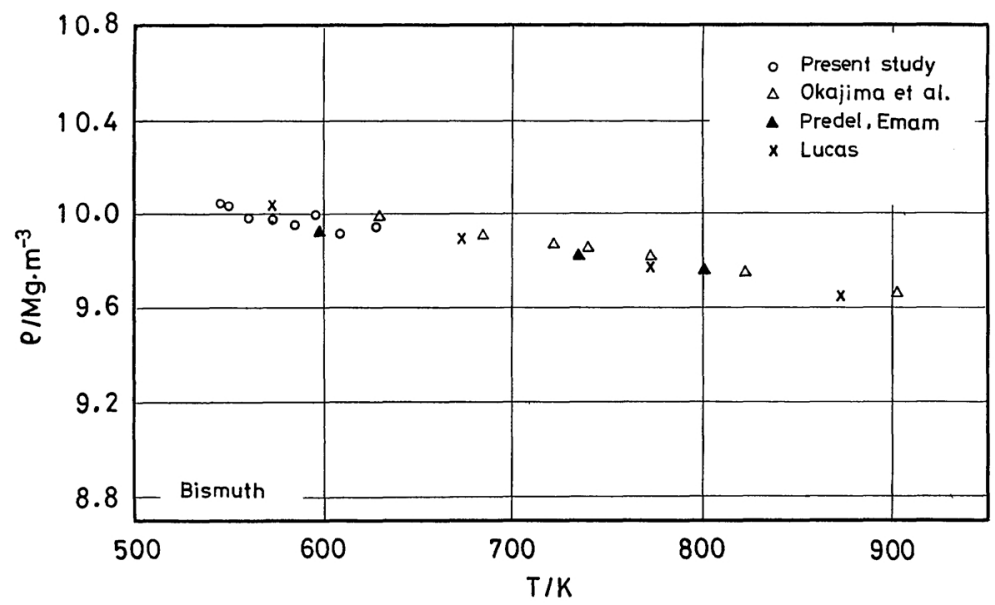

Fig. 10 Comparison of published values with values obtained by the present study on the density of the pure liquid bismuth.

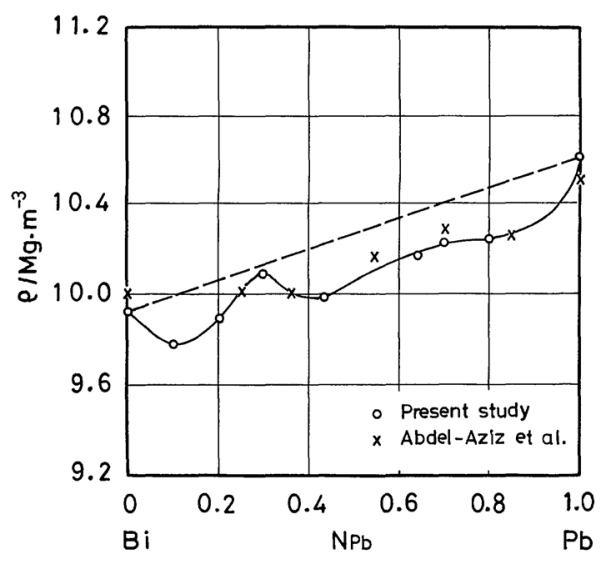

Fig. 11 Comparison between the values of the density of liquid $\mathrm{Pb}-\mathrm{Bi}$ alloys obtained in the present study and those reported in the literature.

reported that the surface activity of the liquid $\mathrm{Pb}-\mathrm{Bi}$ alloys differed from its body activity but that the activity difference between the two was small ${ }^{(20)}$. Therefore, it can be said that the $\mathrm{Pb}-$ $\mathrm{Bi}$ system is the most suitable one to determine such an anomaly by the two different methods. Experiments on the liquid $\mathrm{Pb}-\mathrm{Zn}$ alloys ${ }^{(8)}$ have also revealed that the anomalous behavior of the emf data nearly corresponds to that of the density data.

Thus, although a rigid agreement cannot be expected between both cases, it is emphasized particularly that a common tendency of the E E zone shifting toward higher or lower tem-

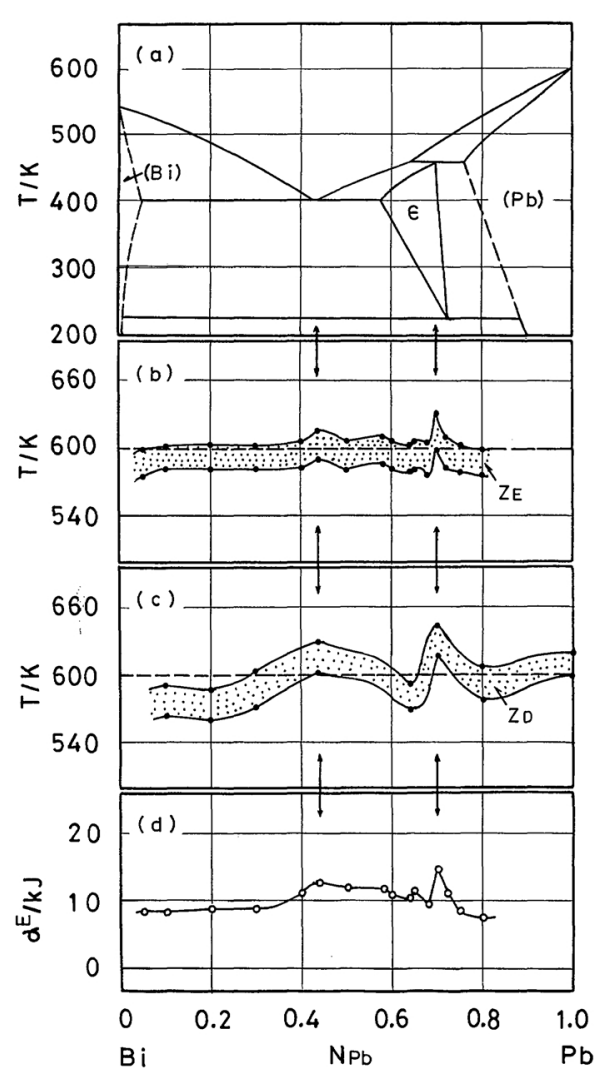

Fig. 12 Comparisons among the E E zones obtained from the emf and the density values, the excess stability and the phase diagram.

perature side is noticeable as shown at $N_{\mathrm{Pb}}=0.437,0.640,0.700$, etc. in Fig. 12. This 
proves that the existence of an $\mathrm{E} E$ zone is beyond doubt. It is also noted that a common trend between both data is found at $N_{\mathrm{Pb}}=$ 0.800 , behaving in a different manner from those at the other compositions. Thus, it can be concluded that the $\mathrm{E} E$ zone can exist in liquid alloys and this distinctive characteristic is a reflection of a similar property of the pure component metal to a great extent.

\section{Summary}

It was made clear from the emf measurements that $\mathrm{E} \mathrm{E}$ zones existed in liquid $\mathrm{Pb}-\mathrm{Bi}$ alloys. The compositional variation of the $\mathrm{E} \mathrm{E}$ zone corresponded well to that of excess stability.

The pre-freezing anomalies of pure lead and bismuth were observed through density measurements, in which this temperature width were about $20 \mathrm{~K}$. The $\mathrm{E} \mathrm{E}$ zones of about $20 \sim 30 \mathrm{~K}$ width observed for the liquid alloys by emf measurements were also observed by density measurements.

It seems certain that the existence of $\mathrm{E} \mathrm{E}$ zones in liquid $\mathrm{Pb}-\mathrm{Bi}$ alloys is a reflection of the pre-freezing anomaly of pure lead.

\section{REFERENCES}

(1) K. Okajima and H. Sakao: Trans. JIM, 29 (1988),
457.

(2) K. Okajima and H. Sakao: Trans. JIM, 19 (1978), 92.

(3) K. Okajima and H. Sakao: Trans. JIM, 23 (1982), 111.

(4) K. Okajima and H. Sakao: Trans. JIM, 24 (1983), 216.

(5) H. S. Strickler and H. Seltz: J. Amer. Chem. Soc., 58 (1936), 2084.

(6) J. F. Elliott and J. Chipman: J. Amer. Chem. Soc., 73 (1951), 2682.

(7) K. Okajima and H. Sakao: Trans. JIM, 21 (1980), 226.

(8) K. Okajima, S. Matsubuchi and H. Sakao: Trans. JIM, 26 (1985), 183.

(9) H. T. Greenaway: J. Inst. Metals, 74 (1947), 133.

(10) B. Predel and A. Emam: J. Less-Common Metals, 18 (1969), 385.

(11) H. R. Thresh, A. F. Crawley and D. W. G. White: Trans. Met. Soc. AIME, 242 (1968), 819.

(12) S. W. Strauss, L. E. Richards and B. F. Brown: Nucl. Sci. Eng., 7 (1960), 442.

(13) L. D. Lucas: Mem. Sci. Rev. Met., 61 (1964), 1.

(14) Abol-Hassan K. Abdel-Aziz and M. B. Kirshah: Z. Metallk., 68 (1977), 437.

(15) K. Okajima and H. Sakao: Trans. JIM, 24 (1983), 223.

(16) J. K. Kristensen and R. M. J. Cotterill: Phil. Mag., 36 (1977), 437.

(17) E. McLaughlin and A. R. Ubbelohde: Trans. Farad. Soc., 56 (1960), 988.

(18) M. M. Qurashi: J. Phys. Chem., 67 (1963), 955.

(19) E. S. Filippov: Izv. V. U. Z. Chernaya Metall., (1975), (7), 119.

(20) K. Okajima and H. Sakao: Trans. JIM, 11 (1970), 180. 